\title{
STREAMLINING MULTINATIONAL LOGISTICAL SUPPORT FROM A NORMATIVE POINT OF VIEW
}

\author{
Sorin PÎNZARIU, Toma PLEȘANU \\ "Nicolae Balcescu" Land Forces Academy, Sibiu, Romania \\ sorinpinz@yahoo.com, tomaplesanu@yahoo.co.uk
}

\begin{abstract}
Conceptual changes in the last period of time in terms of normative regulation of logistical support in post-conflict operations, highlights the fact that most often the conceptual plan takes place before The normative plan and the distances existing between the time of occurrence and implementation of concepts, definitions, summaries, deadlines and regulatory regulation, are becoming larger in particular because of the fluid way in which The aforementioned military actions and due to the involvement or non-involvement of NATO (EU) member States in the efforts of the two organisations.
\end{abstract}

\section{Keywords: post-conflict operations, logistic support, normative, efficiency}

\section{Introduction}

Developments in the last period of time, from the geopolitical and geostrategic environment of the world, highlight a situation similar to that of the cold war period, i.e. since the East-West confruntation could have occurred. In other words, organisations such as NATO and the EU are preparing for a new geopolitical and geostrategic reality which, in one way or another, affects some of the member states. From this point of view, the military bodies of the two organisations are "forced" to evolve faster and more efficiently so as to ensure the security needs of the member states, respectively, depending on the commitments of the two organisations of some of the states with which they cooperate at organisational level.

This type of developments induces at the level of military structures in the NATO and
EU component states changes and conceptual, normative, organisational and procedural transformations, which as well can be seen influence both the way of organizing, Planning and execution of multinational operations, including postconflict type, and logistical domain and its capacity to respond efficiently and effectively to new military challenges.

\section{Ways and ways of effecentisation-} general considerations

The identification of effective ways of responding to logistical support is becoming imperative, especially if we take into account the extremely lengthy periods on which this type of military action is carried out, Extremely high distances from the responsibility areas of international security organisations such as the $\mathrm{UN}$ in general and NATO or the EU in particular. 
It is evident to all those who act in the logistics field that in order to be effective, a simplified or complex logistical support process must ensure the adaptation of the specified system (reaction) to changes that are quite frequent in Operations Theatres (T. Op), given the fluid security environment.

The response of the logistic system to this type of changes must be effective both conceptually, normative, organizational and procedural (aconal).

The experience gained in the Western Balkans, Iraq, Afghanistan and other theatres of operations involving organisations such as NATO (EU), also highlights the fact that regulatory regulation largely depends on the process that shall be carried out in the member states and at the level of the two organisations which, depending on the bureaucracy existing at the level of the entities mentioned, may be longer or shorter.

As a corollary to those outlined above, we believe that the need for normative is required from the strategic level of postconflict operations and ending with the tactical one, where, as a rule, military actions of the type of post-conflict are carried out and where most of the need for adaptation, efficiency and optimization of national and multinational legislation.

Following the analysis of national and existing bibliography within NATO and the EU, as well as on the experience gained in T. Op. in international missions led by the two international security organisations, we believe that for regulatory regulation of the need for efficiency and effectiveness of logistical support actions both explicitly and implicitly, the following ways and ways of efficiency can be followed:

- capitalizing on the experience gained at the tactical level and the feed-back from the combatant forces;

- the establishment of a new approach dictated by the need for continuous modification of existing regulations in the field, at organisational level and in the member states;

- setting different responsibilities for different hierastic levels;

- interconnection and mutual influence of the military and civilian logistics system (given the participation of international economic operators in this type of operation);

- the creation of coherent mechanisms based on the need to adapt existing legislation to the concrete conditions in the operating theatres.

The regulatory changes also reflect the feedback from the tactical level of this type of operation and which must be transposed into the provisions, tactical, operational techniques and procedures that are developed at the level of units/ combat subunits, fighting or logistical support.

In terms of the efficiency of logisticsspecific activities in multinational operations at NATO (EU) and member state level, there is a growing trend in this area, a number of documents coming to bring efficiency in the field approached from the highest level of the pyramid of NATO documents, Council Memoranda (CM) and whose content is transposed into the doctrines specific to each military domain, including the logistical, the Allied Logistics Doctrine Met ( Allied Joint Logistic Doctrines/AJP-4), doctrines supporting these programmatic documents, such as the doctrines specific to each functional domain of logistics, for example, the Allied Logistics Doctrine of Movement and Transport ( Allied Joint Movement and Transportation Doctrine/AJP 4.4), going up to the level of the categories of force doctrines, the Bi-Strategic command level directives, terms, procedures that guide functionally Functional areas of logistical support. 


\section{Streamlining the logistical support from a regulatory perspective within NATO}

In order to achieve efficiency, to ensure an appropriate level of regulatory effectiveness, logistical support activities in multinational operations, working groups are conducted within NATO in the areas of activity, with the participation of the representatives of the member states, where they are adapted, duly amended all the documents regulating the logistics field. These working groups, based on the feed-back from T. Op., the current experience, exercises and practical activities in which the troops of NATO member states work and the need to implement the various standardisation agreements (Standard Agreements/ STANAG) which are elaborated at organisational level (a number of NATO member states due to various, objective or subjective causes, do not implement all STANAG, except with certain limitations).

Taking into account the echelons to which the documents regulating the logistics work are drawn up, we want to emphasise that these levels are aimed at the place, role and mechanisms existing in the organisational plan, among member states and establish a number of responsibilities both collectively and individually. This is how we meet: the national level, the level of the NATO headquarters, the Bi-Strategic level, the two major NATO headquarters: Allied Command Transformation/ACT and ACO, the level of regional commandments (Regional command/RC)/NATO major headquarters, the CJTF level, respectively, the NSPA level.

Each of these structures has well-established roles and responsibilities in terms of how to ensure regulation, streamline and optimise activities specific to logistical support, their fruit materializing in: NATO's logistical support concept; coordinating national and multinational logistical activities; planning of logistical support in a coordinated manner and perspective; synchronisation of various procedures specific to the functional domains of logistics; regulating them from a normative point of view or drafting specific concepts of force category components for various operations conducted by NATO (EU).

Thus, the need for efficiency and optimization of logistical activities makes its presence felt in the way of drafting and modifying the specific principles, the term of efficiency being found in the content of some of them such as flexibility, simplicity and the saving of forces and means, namely synergy[1].

Another approach of this kind is aimed at NATO's logistical concept [2], where in synchronising the procedures specific to the functional domains of logistics, we find specified efficiency phrases and effectiveness.

The same need for efficiency and effectiveness is also found in the content of terms and definitions developed within NATO at the headquarters level, such as the $\mathrm{RSN}$, in terms of how to regulate order mechanisms and procedures and control [3], or in the way of defining the functional domains of logistics such as supply flow and its "push", "pull" or "combined" methods, or in the way of regulating the activity of the financial controller of the T. Op.

\section{Streamlining the regulatory logistical support in some NATO Member States}

This effort to regulate logistics-specific activities in terms of effectiveness and efficiency is carried out not only at the central level of the alliance, but also of the member states which in turn influence the previous process mentioned by national contributions. A special role is held by the US which makes a particularly important contribution to the area addressed, not only through the resources and size of the alliance, but mainly because in the last post- 
conflict operations to which it participated, "played" most of the time the role of LN.

Thus, at the level of the existing regulations in the US military, the terms of efficiency and effectiveness are found in definitions such as the meeting logistics [4], the organisation of the Joint Logistics Enterprise/JLEnt, the module of Coordination and synchronization of the met logistics [5], control of common user Logistics/CUL, logistic information management, respectively, logistic support planning.

In the planning manual of american army operations, FM 100-5, Operations, from the year 1993, in chapter 12 where the Logistic field is addressed, we find terms such as efficiency and effectiveness in definitions such as logistical arrangements, The characteristics of logistics [6], or how to regulate logistical operations [7], respectively as regards the way in which communications lines are regulated, an extremely important device element in ensuring the success of multinational operations.

In our view, of great importance in regulating in terms of the efficiency and effectiveness of specific organisational structures (brigades, battalions, companies, platoons), it has the effort to regulate the formation and specific actions materialised in manuals, regulations, provisions, instructions, etc. Thus, also in the US Army, in FM 4-0 of 2009 "Sustainment" We find terms such as efficiency and effectiveness in the concepts that regulate how responsibilities are established, the mode of action of various human resources-line commands, or the way planning of actions specific to the logistics field.

Last but not least, aspects of efficiency and effectiveness are also found in how to regulate the actions specific to the opening/closing of a T. Op. [8], to achieve the goals, objectives and final state of post- conflict operations and extremely important, the way in which the restoration of the combat capacity of the units participating in multinational operations is regulated and which have been withdrawn from operations.

Examples from the point of view of regulating the need for efficiency and effectiveness of logistical support can also be found in the textbooks of other NATO member states (EU) of which more importantly it seems to us to be the Logistics Doctrine for Joint Operations the 4th edition of the British Army (Joint Doctrine Publication 4-00, Logistics for Joint Operations, Ministry of Defence, 2015). Thus, we find mentioned, in the content of the various regulations in this doctrine, the term of efficiency and effectiveness in the way of overview of logistics, in the way in which the principles of logistics are addressed, in the presentation of the chain of Supply/distribution of products and materials, or presentation of the logistic network established at the level of the British Army.

In terms of command and control, i.e. information on the logistical services that may be offered, there are indications on the line of efficiency and effectiveness in chapter II [9], where the command and control summaries are presented in logistic field at the strategic level, the logistical components of the level of force categories, the level of supply-distribution flow of the material withdrawal chain in the T. Op. (Reverse Supply Chain) and extremely important, how to obtain the unique logistics image on T. Op. (Common Logistics Picture/CLP).

Other references to efficiency and effectiveness are also found in the mode of action of the expeditionary forces, the strategic displacement process in the continental area, in the strategic area (RSOM\&I) and others. 
This process of regulating normative acts elaborated in the field of logistics is also carried out in the Romanian Army. For a good period of time, starting especially with the year 2008, the need to ensure a high degree of efficiency and effectiveness in the logistics field has also been found at the level of the logistic structures of the Ministry of National Defence (M. Ap. N), such as the Directorate of Logistics, Joint Logistics Command, logistic structures at the level of forces, higher education, postsecondary or high school. Thus, they were regulated and found in various definitions and concepts, the term of efficiency and effectiveness in SMG/L-1, the Doctrine of the Logistics of Joint Operations, 2008, L-1, the Regulation of the Logistics of Joint Operations, 2008, L-11, Regulation Equipment Maintenance in the Romanian Army, 2009, L-14/5, Instructions on planning, organizing, coordinating, monitoring and controlling movement execution and transport on air communications routes, 2010, Logistics Strategy Romanian Army, 2010, etc.

Coming closer, in the year 2012, 2014, respectively 2015-2018, were regulated in terms of efficiency and effectiveness and elaborated in this respect, documents on functional domains of logistics such as maintenance (L11/1 vol. 1, Instructions on the maintenance of armoured, automobile and tractor equipment, from the endowment of the Romanian Army in peace, in crisis and war-2012, L11/1 vol. 2, Instructions on the maintenance of armaments and artillery equipment in the Army Romania-2014), movement and transport (L14/4, Intruction on military movement and transport on railway communications routes-2014, L14/1, Instructions on movement and transport operations of large units and military units-2014 ), Supply (LOG 114Instructions on technical insurance with armaments and ammunition in the army in time of peace, as well as during participation in missions and operations outside the territory of the Romanian state-2014), or LOG 1, Classification methodology, establishment of the unit name and codification of articles of the Romanian Army.

In the year 2015, particularly important documents were developed, such as the Doctrine for the multinational logistical support modes in NATO, EU or coalition, L-4/4, Instructions for the application in the Ministry of National Defence of the Rules of Equipment and insurance with equipment for military personnel, during the state of mobilization, war, siege or emergency, as well as for detained persons and prisoners of war, in the year 2018, was elaborated-L4/14 Regulation on the application of the rules for the equipment and insurance of machinery and materials of equipment for the personnel of the Ministry of National Defence in time of peace, which come to regulate in terms of efficiency and effectiveness the mode of endowment and consumption of materials in post-conflict operations led by NATO (EU) or the coalition of forces, respectively for equipping and securing equipment in different situations.

\section{Conclusions}

In conclusion, we support the idea that regulatory efforts must aim at an appropriate balance between the need to ensure logistical actions and the need to ensure the highest level of efficiency and effectiveness to ensure their assurance, the two areas interconnecting and reflecting each other in greater or lesser measure. Thus, for the successful regulation in terms of effectiveness and efficiency of the logistical activities, in our view, a continuous and sustained presence of logistists is required in the working groups organised NATO-led post-conflict operations (EU). 
At the same time, we consider that the lessons identified and learned can be a good opportunity for the proper channelling of the way in which the actions specific to the logistics field are regulated, not only in terms of efficiency and effectiveness, but also of the need for continuity, regardless of time, season or volume of materials to be provided to the combatant forces.

\section{References}

[1] AJP-4, Allied Joint Logistic Doctrine, December 2003, pp. 1-4 - 1-5.

[2] AJP-4, Allied Joint Logistic doctrines, December 2003p. 1-6.

[3] AJP-4, Allied Joint Logistic Doctrines, December 2003, pp. 1-15 - 1-16.

[4] JP 4-0, Joint Publication, USA, Octoer 2013, p. I-2.

[5] JP 4-0, Joint Publication, USA, Octoer 2013, p. III-2

[6] FM 100-5, Operations, USA, 1993, pp. 12-2--12-3.

[7] FM 100-5, Operations, USA, 1993, p. 12-7.

[8] FM 4-0, Sustainement, USA, 2009, p. 4-10

[9] JP 4-00, Logistics for Joint Operations, Ministry of Defence, 2015, pp. 19-31. 